УДК 338.47.021.2:656.21

\title{
ИНТЕГРАЦИЯ МОДЕЛИ УСТОЙЧИВОГО РАЗВИТИЯ В ГРУЗОВЫЕ ЖЕЛЕЗНОДОРОЖНЫЕ ПЕРЕВОЗКИ В РОССИИ: ПРЕДПОСЫЛКИ И ФАКТОРЫ
}

\author{
Каячев Геннадий Фёдорович, \\ GKayachev@sfu-kras.ru \\ Власова Наталья Евгеньевна, \\ st034304@student.spbu.ru \\ Сибирский федеральный университет, \\ Россия, 660041, г. Красноярск, пр. Свободный, 79
}

\begin{abstract}
Каячев Геннадий Фёдорович, доктор экономических наук, профессор кафедры экономики и управления бизнес-процессами Института управления бизнес-процессами и экономики Сибирского федерального университета.
\end{abstract}

Власова Наталья Евгеньевна, магистрант кафедры экономики и управления бизнес-процессами Института управления бизнес-процессами и экономики Сибирского федерального университета.

\begin{abstract}
Актуальность исследования заключается в научной и практической значимости анализа влияния разных групп факторов и выявления тенденций устойчивого развития в России, затрагивающих грузовые железнодорожные компании. Современный период характеризуется ростом количества и обострением глобальных социальных, экономических, экологических, технологических проблем на международном, национальном, региональном и микроуровнях. Данное обстоятельство не только стимулирует, но и требует решительности от государства, общественных структур и бизнеса предпринимать действия, направленные на рациональность использования ресурсов, снижение рисков и угроз, сокращение дисбаланса в социально-экономическом развитии. В контексте происходящих трансформаций с учетом сложившихся в мире практик устойчивого развития необходимо рассматривать доминируюшую по грузообороту сферу грузовых железнодорожных перевозок в России. Она обеспечивает развитие отраслей и регионов, формирует высокий потенциал устойчивости для всех экономических агентов, сглаживая существенные противоречия сегодняшней экономической повестки. При всех современных острых проблемах поиск моделей устойчивого развития для сферы грузовых железнодорожных перевозок остается в зоне внимания как исследователей, так и практиков. В статье рассматриваются ключевые аспекты устойчивого развития, а также преимущества и барьеры внедрения устойчивых практик применительно к российскому рынку грузовых железнодорожных перевозок. Цель исследования: определить предпосылки и выявить ключевые политические, экономические, социальные, технологические, экологические и правовые факторы, имеющие позитивное или негативное влияние на переход к модели устойчивого развития грузовых железнодорожных компаний России. Методология исследования основывается на анализе национальных и отраслевых трендов, определяющих готовность страны в целом и сегмента грузовых железнодорожных перевозок в частности к внедрению устойчивых практик. Результаты показывают, что, с одной стороны, антиустойчивые тенденции доминируют над устойчивыми, осложняют переход к моделям устойчивого развития и являются существенными демотиватороми для бизнеса и домохозяйств. С другой стороны, международная конкуренция из-за глобализации цепей поставок, потенциал энергоэффективности, необходимость замены устаревшей инфраструктуры и оборудования, цифровизация и автоматизация - значительные стимулы для перехода к моделям устойчивого развития.
\end{abstract}

Ключевые слова: Устойчивое развитие, устойчивость, железнодорожные перевозки, грузовые перевозки, устойчивые тренды, устойчивые практики. 


\section{Концепция устойчивого развития и ее роль для транспортного сектора}

Существующие подходы к определению устойчивого развития при всей их вариативности опираются на представленное в 1987 г. и в дальнейшем расширенное определение ООН. Устойчивое развитие представляет процесс институциональных изменений, при которых потребление ресурсов, направления инвестирования и технологического развития происходят сбалансировано для обеспечения текущего и будущего потенциала удовлетворения потребностей общества с точки зрения социальных, экологических и экономических аспектов [1].

Разработка принципов и концептуальное осмысление содержания и механизма реализации устойчивого развития отражает потребность эффективной реакции государств и бизнеса на новые вызовы. Стимулы в появлении концепции устойчивого развития обусловлены прежде всего необходимостью решения сложившихся глобальных негативных трендов и масштабностью общемировых проблем. Глобальность проблем представлена одновременным появлением совокупности социальных, экологических, экономических, политических и иных факторов, которые негативно влияют на мировое сообщество и окружающую среду, угрожают существованию и развитию человечества и не могут быть разрешены без международной кооперации [2]. К проблемам глобального характера в первую очередь относятся разрушение экосистем, изменения климата, социальное неравенство, исчерпание природных ресурсов, голод, локальные войны [3]. Глобализация длительное время является неотъемлемой частью всех сфер жизни общества, основными из которых являются социальная, экономическая, политическая и духовная. События, происходящие в одном государстве, затрагивают другие страны или весь мир в целом. Так, события, повлекшие за собой пандемию, падение цен на нефть, создали предпосылки для мирового экономического кризиса. Наиболее вероятен спад в экономике, вызванный приостановкой производств, закрытием границ, убытками компаний и индивидуальных предпринимателей, занятых в сфере развлекательных услуг (туризм, спортивные и культурные массовые мероприятия, пассажироперевозки и смежные отрасли) [4]. Однако несмотря на вынужденное искусственное сдерживание глобальной человеческой мобильности и структурные кризисные процессы, грузоперевозки между городами и странами продолжают осуществляться. Международная специализация и разделение труда не позволяют прекратить этот процесс без катастрофических экономических и социальных последствий. Таким образом, грузовые перевозки являются неотъемлемой частью глобализации и могут выступать как способы решения глобальных проблем или в случае неустойчивого развития - как источники их возникновения.

Исторически впервые международные принципы устойчивого развития были официально закреплены соглашением между 115 странами 16 июня 1972 г. на Конференции ООН по проблемам окружающей среды. Итогом конференции стала разработка 26 принципов по охране окружающей среды и развития человечества [5]. Дальнейшее усугубление глобальных проблем потребовало новых инициатив. В 1987 г. был издан Доклад Всемирной комиссии по вопросам окружающей среды и развития, акцентирующий внимание на практическом подходе к решению глобальных проблем через устойчивое развитие. В доклад вошли конкретные инновационные и реалистичные мероприятия по достижению целей устойчивого развития, укрепления глобальной кооперации, увеличения осведомленности индивидуумов, общественных организаций, бизнеса, правительств об устойчивом развитии [1]. Бизнес с устойчивым развитием связывает концепция тройного критерия («triplebottomline»). Так, организации должны учитывать не только финансовые, но и социальные и экологические результаты деятельности. Это 
же относится и к индивидуумам, общественным организациям и государствам в целом [6]. Одним из первых концепцию тройного критерия описал Ф. Спрекли [7] в 1981 г., а в 1997 г. Дж. Элкингтон представил её комплексный анализ [8]. В 1992 г. состоялся Саммит Земли, итогом которого стала Декларация Рио-де-Жанейро по окружающей среде и развитию. В ней были утверждены 27 принципов, связанных с решением вопросов вредных производств, диверсификации энергии, снижения выбросов, восстановлением экосистем и снижением негативного влияния на здоровье населения [9]. В 2000 г. в Нью-Йорке состоялся Саммит тысячелетия, итогом которого стала Декларация тысячелетия Организации Объединенных Наций [10]. В ней были закреплены принципы устойчивого развития в сфере обеспечения мира, безопасности и разоружения; социально-экономического развития; охраны окружающей среды; обеспечения прав и свобод человека. В 2012 г. состоялась Конференция ООН по устойчивому развитию - «Рио + 20» [11], по итогам которой 192 государства подтвердили своё согласие действовать в соответствии с устойчивым развитием. На 2020 г. главным документом устойчивого развития является «Преобразование нашего мира: повестка дня в области устойчивого развития на период до 2030 года» от 2015 г. [12]. В повестке ООН закреплены 17 целей и 169 задач по достижению устойчивого развития в экономическом, социальном и экологическом аспектах.

В настоящее время исследовательская активность в данной области достаточно высока и объяснима неразрешенностью наиболее острых противоречий структурного характера для развитых и развивающихся стран. Государства, исследовательские агентства, компании и научные сообщества активно изучают проблематику устойчивого развития. Так, обоснованы и утверждены в международных документах принципы устойчивого развития [13]. Классифицированы стимулы и барьеры применения устойчивых практик государствами, бизнесом и обществом $[14,15]$. Представлены сценарии перехода транспортного сектора к политике энергоэффективности и снижению выбросов [16]. Рассмотрены проблемы устойчивости глобальных цепей поставок [17-19]. Дополнены ключевые показатели эффективности грузовых железнодорожных компаний с учётом критериев устойчивости [20]. Однако существуют пробелы в теоретическом осмыслении и методическом обосновании процессов внедрения моделей устойчивого развития в железнодорожные грузоперевозки. Требуются адаптация существующих исследований и разработка рекомендаций по созданию и поэтапному переходу к моделям устойчивого развития железнодорожных грузовых компаний, учитывающих специфику отрасли, как в России, так и за рубежом. Кроме того, необходимо выбрать и адаптировать подходящую комплексную систему оценки эффективности модели с привязкой к стратегиям компании и целям её устойчивого развития.

\section{Устойчивое развитие грузового железнодорожного транспорта}

Во всём мире транспорт, с одной стороны, является одним из источников негативного влияния на окружающую среду, а с другой - имеет высокий потенциал снижения негативного эффекта, обеспечивает мобильность в развитии всех экономических отраслей и сфер. В настоящее время грузовые железнодорожные перевозки имеют высокую пропускную способность, позволяют перевозить грузы на большие расстояния, служат альтернативой автомобильным грузоперевозкам по совокупному показателю цены, качества, скорости и влияния на окружающую среду. Железнодорожный транспорт обходит проблему городских транспортных ограничений, характеризуется низкими выбросами углекислого газа, обеспечивает мобильность ресурсов от места добычи до места переработки, являясь важной частью цепочки создания ценности. Так, обеспе- 
чивая 8 \% всех пассажирских перевозок и 7 \% грузовых в мире, железнодорожный сектор потребляет только $2 \%$ энергии от всего транспортного сектора и отвечает за $0,3 \%$ выбросов углекислого газа $\left(\mathrm{CO}_{2}\right)$ от сжигания ископаемого топлива и за 0,3 \% выбросов в виде твердых частиц РМ2,5 [21]. Зарубежные железнодорожные компании США, Канады, Китая, Японии, стран ЕС постепенно внедряют практики устойчивости. Среди них - снижение выбросов $\mathrm{CO}_{2}$ и шумового загрязнения. Политика энергоэффективности в Швейцарии обеспечила достижение показателя в 90 \% энергии для поездов посредством гидроэнергетики [22]. Бережливое производство и экономика замкнутого цикла в Германии обеспечили покрытие перронов и железнодорожных станций брусчаткой из $100 \%$ переработанных материалов [23]. Увеличение пропускной способности скоростных электрифицированных линий в Китае осуществлено за счёт внедрения стандартов увеличенных вертикальных зазоров для грузоперевозок многоярусными контейнерами на скорости до160 км/ч [24].

В России рынок железнодорожных грузоперевозок является монополией в сегменте владения инфраструктурой и тяговым подвижным составом, что накладывает свой отпечаток на развитие отрасли. Важной особенностью является то, что доля железнодорожного транспорта в структуре грузооборота в стране составляет около $46 \%$ на 2019 г., а без учёта трубопроводного транспорта - 87,2 \% [25]. Кроме того, Россия занимает третье место в мире по протяженности железнодорожных линий общего пользования (86 тыс. км) и имеет высокий показатель средней дальности перевозок 1 тонны груза (2013 км) [26]. Важным показателем, характеризующим устойчивость грузовых железнодорожных перевозок с точки зрения энергоэффективности, является энергоёмкость, измеряемая в кДж/т-км. Грузовые железнодорожные перевозки наиболее энергоэффективны в России за счет синергии загруженности и электрификации (см. рисунок) [21].

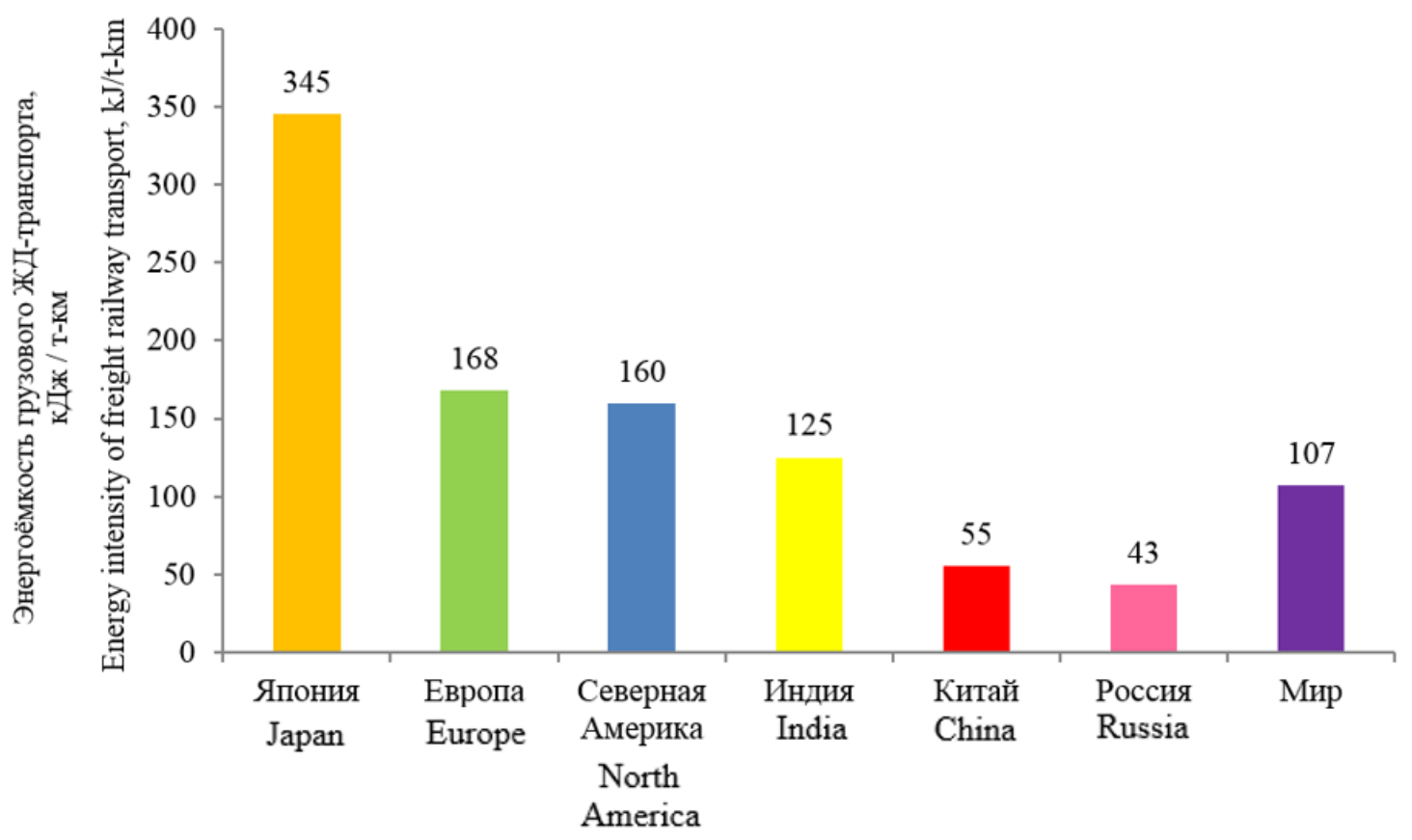

Рисунок. Энергоёмкость грузового ж/д транспорта, кДж/m-км Figure. Energy intensity of freight railway transport, $\mathrm{kJ} / \mathrm{t}-\mathrm{km}$ 
Эффективность развития грузовых железнодорожных перевозок на современном этапе с учетом обострения глобальных проблем в мирохозяйственных процессах предполагает учет всей совокупности предпосылок и факторов и их влияния на развитие отрасли. В этой связи важно методически выделить те политические, экономические, социальные, технологические, экологические и нормативные предпосылки и факторы, которые влияют на темпы и ограничения в процессе перехода к модели устойчивого развития в сфере грузовых железнодорожных перевозок.

В качестве предпосылок перехода грузовых железнодорожных компаний к реализации модели устойчивого развития выделим достаточно высокий уровень научнометодического обоснования прогнозных документов, определяющих вектор трансформации сферы. В частности, утверждены и реализуются стратегии и программы, затрагивающие элементы устойчивого развития: Энергетическая стратегия России до 2030 г., Стратегия экологической безопасности РФ на период до 2025 г., Стратегия пространственного РФ развития до 2025 г., Стратегия развития минерально-сырьевой базы России до 2035 г., Стратегия развития железнодорожного транспорта в РФ до 2030 г. и др. [27].

Важной предпосылкой эффективного внедрения практик устойчивого развития является доминирующая роль государства, являющегося регулятором и единственным акционером господствующей в отрасли компании ОАО «РЖД». Правительство РФ ежегодно субсидирует проекты в железнодорожной отрасли, реализуемые холдингом. Поэтому внедрение устойчивых практик встретит минимальное сопротивление в отрасли.

Еще одной значимой предпосылкой является уровень осознания необходимости изменений в сторону устойчивости различными группами населения, что способствовало укреплению общественной позиции, влияющей на характер социальноэкономических и экологических преобразований [28].

В качестве предпосылки эффективного внедрения концепции устойчивого развития выступает достаточно высокий финансово-экономический потенциал железнодорожной отрасли

И, наконец, процессы глобализации, несмотря на все проблемы и противоречия современного этапа, остаются важнейшей предпосылкой необходимости перехода к устойчивому развитию сферы железнодорожных перевозок.

Наряду с предпосылками принципиально выделить факторы, противоречиво влияющие на процессы реализации концепции устойчивого развития в сфере железнодорожного транспорта. Основываясь на методологии PESTEL, в совокупности разнообразных факторов выделим основные политические, экономические, социальные, технологические, экологические и правовые факторы, влияющие на внедрение принципов устойчивого развития.

\section{Политические факторы (Р)}

P1. Федеративное устройство. Существуют разрывы в устойчивом развитии между регионами. Для большинства богатых ресурсами регионов с преимущественно сырьевым сектором по-прежнему характерна неблагоприятная экологическая ситуация, что ограничивает возможности устойчивости развития территорий.

P2. Национальная безопасность, экономическое и геополитическое положение. Истощение ресурсов, миграция, международные конфликты усиливаются при ресурсном дисбалансе между странами. Однако протяженность территории и обилие природных ресурсов в России в среднесрочной перспективе оградят страну от катастрофических последствий разрушения экосистем, что замедляет переход к устойчивому развитию. 


\section{Экономические факторы (E)}

Е1. Медленный переход к зелёной экономике, доминирование сырьевой модели экономики, противоречащей устойчивому развитию. Это отражается в ряде документов: Стратегия экологической безопасности Российской Федерации на период до 2025 г., Основы государственной политики в области экологического развития РФ до 2030 г. Однако сложившиеся антиустойчивые тренды замедляют этот переход. К ним относятся высокая доля загрязняющих отраслей, износ основных фондов, сырьевой экспорт, слабое природоохранное законодательство [29].

Е2. Определенный дисбаланс государственной экономической поддержки. Значительная налоговая нагрузка сохраняется в обрабатывающих отраслях с небольшим экологическим воздействием в сравнении с отраслями сырьевой направленности. Так, для целей устойчивого развития необходимо изменение налоговой системы в части поддержки энергоэффективных и высокотехнологичных производств [29].

E3. Слабый приток инвестиций частных компаний из-за высоких входных барьеров на рынке железнодорожных грузоперевозок.

E4. Влияние международной торговли. 60, 30 и 10 \% грузоперевозок приходится соответственно на внутренние перевозки, экспорт, совокупные импорт и транзит. Следовательно, железнодорожные грузоперевозки зависят от международной торговли и санкций [30].

E5. Растущая конкуренция с автомобильным транспортом из-за увеличения маршрутов, протяженности автодорог, количества придорожных складов, высокой конкуренции автоперевозчиков, более низкого роста цен [31].

\section{Социальные факторы (S)}

S1. Культура устойчивого развития. Текущая осведомленность и понимание устойчивого развития в России довольно низки. Однако $72 \%$ российских потребителей учитывают экологические характеристики приобретаемых товаров и услуг, что говорит о росте осведомленности [32]. Кроме того, россияне всё чаще занимают активную гражданскую позицию, защищая социальные и экологические права [28].

S2. Отток человеческого капитала за границу. По различным оценкам уехать планируют 46 \% опрошенных специалистов с высшим образованием и 57 \% молодежи [33].

S3. Обеспечение мобильности. Железные дороги проходят через 77 из 85 субъектов РФ, перевозя пассажиров и грузы, влияя на развитие экономики и региональную интеграцию [24].

$\mathrm{S} 4$. Создание рабочих мест компаниями отрасли. Главная компания отрасли ОАО «РЖД» - является одним из крупнейших работодателей в России, получая поддержку государства и неся ответственность перед обществом и сотрудниками через соблюдение принципов корпоративной социальной ответственности (КСО).

S5. Благотворительная деятельность железнодорожных компаний. Компании отрасли способствуют сохранению объектов культурного наследия, возрождению храмов и монастырей; оказывают помощь детям, находящимся в трудной жизненной ситуации; поддерживают молодежные инициативы и проекты; строят бассейны, больницы, центры реабилитации, образовательные учреждения.

\section{Технологические факторы (T)}

T1. Потенциал рационального природопользования. Переход к зелёной экономике имеет высокий потенциал роста эффективности использования уже имеющихся в обо- 
роте сырья и материалов без увеличения добычи, что приведёт к снижению удельных затрат природных ресурсов и объемов загрязнений [29].

Т2. Потенциал энергоэффективности. 60-80\% энергетической инфраструктуры не эффективно из-за устаревания, 90 \% промышленных отходов не перерабатывается, что говорит об упущенных возможностях [34]. Железнодорожный транспорт в России считается самым экологичным: $0,72 \%$ - это выбросы в атмосферу от стационарных источников; $1 \%$ - от передвижных источников; 0,09 \% по сбросу сточных вод в реки и озера; 0,08 \% - по формированию отходов производства. По протяжённости электрифицированных магистралей Россия занимает первое место, имея потенциал дальнейшей электрификации.

Т3. Тип перевозимых грузов. 70 \% железнодорожного грузооборота приходится на каменный уголь, нефть и нефтепродукты, строительные грузы, руду и черные металлы. Это, во-первых, требует ужесточения контроля в области загрязнения территорий перевозимыми грузами в результате аварий, утечек и иных потерь по территориям следования составов, во-вторых, оптимизации систем мониторинга подвижного состава, вызванного повышенным износом из-за типа перевозимых грузов [35].

\section{Экологические факторы (E)}

Е1. Высокая доля городов с неблагоприятной экологической обстановкой. Большинство городов России фиксируют постоянные превышения предельно допустимых концентраций вредных веществ, увеличивая расходы на здравоохранение и ухудшая здоровье и качество жизни населения [36, 37].

E2. Накопленный экологический вред. В настоящее время уделяется мало внимания вопросами ликвидации накопленного экологического вреда. Явно недостаточны финансовая компенсация экологического и социального ущерба и выполнение природоохранных мероприятий [38].

\section{Правовые факторы (L)}

L1. Отсутствие чётких механизмов реализации стратегии устойчивого развития на уровне страны и регионов при наличии законодательной базы. С тех пор, как в 1996 г. была утверждена Концепция перехода Российской Федерации к устойчивому развитию, принят ряд законодательных актов, в том числе «Основы государственной политики в области экологического развития России на период до 2030 г. (1912 г.)» [39] значительных позитивных изменений в реальной практике устойчивого развития не произошло.

L2. Принцип «загрязнитель платит» должен заработать на практике [29]. Отсутствие жёсткого экологического и природоохранного законодательства позволяет компаниям снижать затраты не за счёт роста эффективности деятельности, а за счёт экономии на экологических мерах.

Рынок грузовых железнодорожных перевозок, являясь частью глобальной экономики, играет важную роль в переходе к устойчивому развитию и в зависимости от проводимых преобразований, может как усложнить, так и ускорить процесс перехода. На национальном уровне есть ряд предпосылок для устойчивого развития сферы железнодорожных перевозок. Вместе с тем геополитическое положение обусловливает медленный переход к зелёной экономике, т. к. проблема исчерпания ресурсов в среднесрочной перспективе не является приоритетной. Реальное внедрение практик устойчивого развития не носит всеобъемлющего и системного характера. Низкая эффективность мер по борьбе с постоянно растущей долей городов с неблагоприятной экологи- 
ческой обстановкой и накопленным экологическим вредом требует пересмотра существующей политики в области защиты окружающей среды и обеспечения здоровья и благополучия граждан.

Однако существует ряд предпосылок и стимулов устойчивого развития. Международное взаимодействие и влияние международной торговли обязывают Россию вводить новые стандарты в области экологии, безопасности, качества и корпоративной социальной ответственности. Стратегическая значимость железнодорожной отрасли, обеспечение мобильности, создание рабочих мест служат индикатором необходимости создания среды для внедрения принципов устойчивого развития. С точки зрения грузовых железнодорожных компаний, внедрение практик устойчивого развития обусловливается объективными предпосылками, но сопряжено с рядом барьеров. Так, дисбаланс государственной экономической поддержки, выражающийся в отсутствии законодательных и налоговых стимулов для отраслей и компаний снижать нагрузку на окружающую среду на фоне льгот и субсидий добывающим и обрабатывающим компаниямзагрязнителям, замедляет устойчивое развитие компаний. Преобладание «грязных» перевозимых грузов вроде угля и нефтепродуктов усиливает нагрузку на подвижной состав, увеличивая износ. Варьирующиеся климатические условия и особенности географии усложняют и удорожают разработку и внедрение технологий.

Однако железнодорожным компаниям необходимо внедрять практики устойчивого развития по ряду причин. Господдержка отрасли позволяет её ведущей компании реализовывать масштабные программы и мегапроекты согласно стратегиям развития железнодорожного транспорта в РФ до 2030 г. Растущая конкуренция с автомобильным транспортом и на глобальном уровне предполагает оптимизацию деятельности железнодорожных компаний и поиск эффективных решений. Потенциал рационального природопользования и роста энергоэффективности за счёт увеличения электрофицированных линий, обновления устаревшего подвижного состава и инфраструктуры, внедрения современных технологий прогнозирования, мониторинга и оперирования обеспечит снижение издержек и большую финансовую устойчивость компаний.

\section{СПИСОК ЛИТЕРАТУРЫ}

1. Report of the World Commission on Environment and Development: our Common Future // United Nations. Oxford University Press. - 1987. URL: http://www.un-documents.net/our-common-future.pdf (дата обращения 02.02.2020).

2. Bhargava V. Global issues for global citizens. - Washington, D.C.: World Bank, 2006. URL: http://siteresources.worldbank.org/EXTABOUTUS/Resources/Chapter1.pdf (дата обращения 02.02.2020).

3. Global issues overview // United Nations. URL: http://www.un.org/en/sections/issues-depth/global-issuesoverview/ (дата обращения 03.02.2020).

4. Irwin N. Something weird is happening on Wall Street, and not just the stock sell-off // The New York Times Company, 2020. URL: https://www.nytimes.com/2020/03/12/upshot/markets-weird-coronavirus. html?auth=link-dismiss-google1 tap (дата обращения 14.03.2020).

5. Report of the United Nations Conference on the Human Environment. - Stockholm, 5-16 June 1972. - New York: UN, 1973. URL: https://digitallibrary.un.org/record/523249?ln=en\#record-files-collapse-header (дата обращения 03.03.2020).

6. Amos A., Uniamikogbo E., Atu G. Sustainability and triple bottom line: an overview of two interrelated concepts // Igbinedion University Journal of Accounting. - 2016. - V. 2. - P. 88-126. URL: https://www.researchgate.net/publication/322367106_sustainability_and_triple_bottom_line_an_overview_ of_two_interrelated_concepts (дата обращения 03.03.2020).

7. Spreckley F. Social audit: a management tool for co-operative working. - UK: Beechwood College, 1987. - 47 p.

8. Elkington J. Cannibals with forks: the triple bottom line of 21 st century businesses // Environmental Quality Management. - 1998. - № 8 (1). - P. 37-51. DOI: 10.1002/tqem.3310080106.

9. UN Conference on Environment and Development. United Nations, 1992. URL: https://sustainabledevelopment.un.org/content/documents/Agenda21.pdf (дата обращения 03.03.2020). 
10. Millennium Summit. - United Nations, 6-8 September $2000 . \quad$ URL: http://www.un.org/en/events/pastevents/millennium_summit.shtml (дата обращения 03.03.2020).

11. United Nations Conference on Sustainable Development, Rio+20. - United Nations, 2012. URL: https://sustainabledevelopment.un.org/rio20 (дата обращения 03.03.2020).

12. Transforming our world: the 2030 agenda for sustainable development. - United Nations, 2015. URL: https://sustainabledevelopment.un.org/post2015/transformingourworld (дата обращения 03.03.2020).

13. Sustainable Development Goals. - United Nations Division for Sustainable Development Goals. URL: https://sustainabledevelopment.un.org/?menu=1300 (дата обращения 05.03.2020).

14. Sustainable Logistics: an Introduction to the Concept and Case Studies from Germany / T. Bernecker, D. Lohre, V. Poerschke, J-J. Roth, H. Grandjot. - Berlin: German Partnership for Sustainable Mobility, 2014. 60 p. URL: https://www.german-sustainable-mobility.de/wp-content/uploads/2015/01/gpsm-logisticsGRUEN-5.compressed.pdf (дата обращения 05.03.2020).

15. Бобылев C., Перелёт Р. Экологическая информация и образование в области устойчивого развития // Устойчивое развитие в России / под ред. С. Бобылева и Р. Перелета. URL: https://www.austausch.org/files/DRA/Publikationen/Nachhaltige_Entwicklung_in_Russland.pdf (дата обращения 05.03.2020).

16. Rail and sustainable development. - International Union of Railways, 2011. URL: https://www.vialibreffe.com/pdf/7180.pdf (дата обращения 05.03.2020).

17. McKinsey on sustainability \& resource productivity // Sustainability \& Resource Productivity. - 2016. № 4. URL: https://www.mckinsey.com/ /media/McKinsey/Business Functions/Sustainability/Our Insights/McKinsey on Sustainability and Resource Productivity Number 4/McKinsey on Sustainability and Resource Productivity Issue 4.ashx (дата обращения 05.03.2020).

18. Sustainability in logistics and supply chain management // Hamburg International Conference on Logistics. 2015. URL: https://tore.tuhh.de/bitstream/11420/1266/1/HICL2015-Vol21-SustainabilityinLogisticsand SupplyChain Management.pdf (дата обращения 05.03.2020).

19. Grabara J. Sustainable logistics management // EdituraUniversităţii "Lucian Blaga" din Sibiu. - 2013. URL: https://www.researchgate.net/publication/266854152_sustainable_logistics_management (дата обращения 05.03.2020).

20. Guilherme F. Measuring performance in rail freight transportation companies // International Business Research. - 2017. - V. 10. - № 11. DOI: 10.5539/ibr.v10n11p117.

21. The future of rail. Opportunities for energy and the environment // International energy agency. - 2019. 175 p. URL: https://www.shop-etf.com/en/the-future-of-rail (дата обращения 05.03.2020).

22. Sustainability strategy. - SBB Swiss Federal Railways, 2020. URL: https://company.sbb.ch/en/thecompany/responsibility-society-environment/sustainability-strategy.html (дата обращения 21.02.2020).

23. Eco-friendly paving stones from AB. - Deutsche Bahn AG, 2020. URL: https://gruen.deutschebahn.com/en/measures/pavingstones (дата обращения 21.02.2020).

24. Evans B. SA should look to China for sustainable rail solutions. - EE Publishers (Pty) Ltd., 2014. URL: https://www.ee.co.za/article/sa-look-china-sustainable-rail-solutions.html (дата обращения 23.02.2020).

25. РЖД в цифрах // OAO «Российские железные дороги». URL: https:/www.rzd.ru/static/public/ru? STRUCTURE_ID=5232 (дата обращения 02.03.2020).

26. Обзор отраслй грузоперевозок в России, 2019 год // ООО «Эрнст энд Янг - оценка и консультационные услуги». URL: https://www.ey.com/publication/vwluassets/ey-transportation-services-2019rus/\$file/ey-transportation-services-2019-rus.pdf (дата обращения 02.03.2020).

27. Отраслевые документы стратегического планирования // Сайт Правительства России. URL: http://government.ru/rugovclassifier/625/events/ (дата обращения 14.03.2020).

28. Проворная Е. Митя Савелов (Change.org): «Личные истории - самые главные двигатели любых перемен» // GQ. URL: https://www.gq.ru/success/mitya-savelov-changeorg (дата обращения 01.03.2020).

29. Бобылев С., Перелёт Р. Устойчивое развитие и «зеленая» экономика в России: актуальная ситуация, проблемы и перспективы // Устойчивое развитие в России. URL: https://www.austausch.org/ files/DRA/Publikationen/Nachhaltige_Entwicklung_in_Russland.pdf (дата обращения 05.03.2020).

30. Нуреев Р. Экономические санкции против России: ожидания и реальность: монография. - М.: КНОРУС, 2017. - 194 c.

31. Лукьянова О., Хусаинов Ф. О конкуренции железнодорожного и автомобильного транспорта на рынке грузовых перевозок // Вектор транспорта. - 2014. - № 2. - С. 28-43.

32. Стратегия устойчивого развития // Устойчивый бизнес. URL: http://csrjournal.com/strategiyaustojchivogo-razvitiya (дата обращения 22.02.2020).

33. Овсянников И. Eurasianet (США): Россия переживает новый всплеск эмиграции. URL: https://inosmi.ru/social/20190716/245475409.html (дата обращения 29.02.2020). 
34. Эффективная Россия. Производительность как фундамент роста / Д. Бакатина, Ж.-П. Дювьесар, В. Клинцов, К. Крогманн, Я. Ремес, Е. Солженицын, И. Швакман. URL:http://gtmarket.ru/files/news/ 1986/MGI_Effective_Russia_Productivity_Growth_as_the_Foundation_2009.pdf (дата обращения 03.03.2020).

35. «BCTO-2» переориентирует часть нефти с железной дороги на трубопроводный транспорт. URL: http://www.gudok.ru/freighttrans/?ID=1302708 (дата обращения 03.03.2020).

36. Писарева В. Общие проблемы экологии Российской Федерации // Международный институт гуманитарно-политических исследований. URL: http://www.igpi.ru/monitoring/1047645476/oct_93/ 1058173260.html (дата обращения 20.02.2020).

37. В 20 \% городов России загрязнение воздуха оценивается как высокое и очень высокое // Информационное агентство TACC. URL: https://tass.ru/obschestvo/3913243 (дата обращения 20.02.2020).

38. Поправко Н. Контроль за исполнением природоохранного законодательства, обзор судебной практики // Устойчивое развитие в России / под ред. С. Бобылева и Р. Перелета. URL: https://www. austausch.org/files/DRA/Publikationen/Nachhaltige_Entwicklung_in_Russland.pdf (дата обращения 05.03.2020).

39. Хмелёва Е. Правовые аспекты: состояние правового поля и правовой практики // Устойчивое развитие в России / под ред. С. Бобылева и Р. Перелета. URL: https://www.austausch.org/files/DRA/ Publikationen/Nachhaltige_Entwicklung_in_Russland.pdf (дата обращения 05.03.2020).

Поступила 15.03.2020 г. 
UDC 338.47.021.2:656.21

\title{
INTEGRATION OF THE SUSTAINABLE DEVELOPMENT MODEL IN RAIL FREIGHT TRANSPORTATION IN RUSSIA: BACKGROUND AND CURRENT FACTORS
}

\author{
Gennady F. Kayachev, \\ GKayachev@sfu-kras.ru \\ Natalia E. Vlasova, \\ st034304@student.spbu.ru \\ Siberian Federal University,
}

79, Svobodny avenue, Krasnoyarsk, 660041, Russia.

Gennady F. Kayachev, Dr. Sc., professor, Siberian Federal University.

Natalia E. Vlasova, master student, Siberian Federal University.

The relevance of the study lies in the scientific and practical significance of analyzing the influence of different groups of factors and identifying sustainable development trends in Russia affecting freight railway companies. The modern period is characterized by an increase in the number and exacerbation of global social, economic, environmental, technological problems at the international, national, regional and micro levels. This circumstance does not simply stimulate, but also requires decisiveness from the state, public structures and businesses to take actions aimed at the rational use of resources, reducing risks and threats, mitigating imbalances in socio-economic development. In the context of the ongoing transformations, taking into account the prevailing practices of sustainable development in the world, it is necessary to consider the sphere of freight rail transportation in Russia, which is dominant in terms of freight turnover. It ensures the development of industries and regions, forms a high potential for sustainability for all economic agents, smoothing out the essential contradictions of today's economic agenda. Despite all the current acute problems, the search for sustainable development models for rail freight remains in the focus of attention of both researchers and practitioners. The article discusses the key aspects of sustainable development, as well as the advantages and barriers to implementation of sustainable practices in relation to the Russian market of rail freight transportation. The aim of this study is to identify key political, economic, social, technological, environmental and legislative factors that have positive or negative impact on implementation of sustainable development models by freight railway companies in Russia. The research methodology is based on the analysis of national and industry trends that determine the willingness of the country as a whole and the rail freight segment in particular to implement sustainable practices. The results of the study show that, on the one hand, anti-sustainable tendencies dominate the sustainable ones, complicate the implementation of sustainable development models and are strong demotivators for businesses and households. On the other hand, international competition due to globalization of supply chains, energy efficiency potential, the need to replace obsolete infrastructure and equipment, digitalization and automation are significant incentives for the transition to sustainable development models.

Key words: Sustainable development, sustainability, rail transportation, freight transportation, sustainable trends, sustainable practices.

\section{REFERENCES}

1. Report of the World Commission on Environment and Development: our common future. United Nations, Oxford University Press, 1987. Available at: http://www.un-documents.net/our-common-future.pdf (accessed 2 February 2020).

2. Bhargava V. Global issues for global citizens. Washington, D.C, World Bank, 2006. Available at: http://siteresources.worldbank.org/extaboutus/resources/chapter1.pdf (accessed 2 February 2020). 
3. Global issues overview. United Nations. Available at: http://www.un.org/en/sections/issues-depth/globalissues-overview/ (accessed 3 February 2020).

4. Irwin N. Something weird is happening on Wall Street, and not just the stock sell-off. The New York Times Company, 2020. Available at: https://www.nytimes.com/2020/03/12/upshot/markets-weirdcoronavirus.html?auth=link-dismiss-google1tap (accessed 14 March 2020).

5. Report of the United Nations Conference on the Human Environmentю Stockholm, 5-16 June 1972. New York, UN, 1973. Available at: https://digitallibrary.un.org/record/523249?ln=en\#record-files-collapseheader (accessed 3 March 2020).

6. Amos A., Uniamikogbo E., Atu G. Sustainability and triple bottom line: an overview of two interrelated concepts. Igbinedion University Journal of Accounting, 2016, vol. 2, pp. 88-126. Available at: https://www.researchgate.net/publication/322367106_sustainability_and_triple_bottom_line_an_overview_o f_two_interrelated_concepts (accessed 3 March 2020).

7. Spreckley F. Social audit: a management tool for co-operative working. UK, Beechwood College, $1987,47 \mathrm{p}$.

8. Elkington J. Cannibals with forks: the triple bottom line of $21^{\text {st }}$ century businesses. Environmental Quality Management, 1998, no. 8 (1), pp. 37-51. DOI: 10.1002/tqem.3310080106.

9. UN Conference on Environment and Development. United Nations, 1992. Available at: https://sustainabledevelopment.un.org/content/documents/Agenda21.pdf (accessed 3 March 2020).

10. Millennium Summit. United Nations, 6-8 September 2000. Available at: http://www.un.org/en/events/pastevents/millennium_summit.shtml (accessed 3 March 2020).

11. United Nations Conference on Sustainable Development, Rio+20. United Nations, 2012. Available at: https://sustainabledevelopment.un.org/rio20 (accessed 3 March 2020).

12. Transforming our world: the 2030 agenda for sustainable development. United Nations, 2015. Available at: https://sustainabledevelopment.un.org/post2015/transformingourworld (accessed 3 March 2020).

13. Sustainable development goals. Available at: https://sustainabledevelopment.un.org/?menu=1300 (accessed 5 March 2020).

14. Bernecker T., Lohre D., Poerschke V., Roth J-J., Grandjot H. Sustainable logistics: an introduction to the concept and case studies from Germany. Berlin, German Partnership for Sustainable Mobility, 2014. 60 p. Available at: https://www.german-sustainable-mobility.de/wp-content/uploads/2015/01/gpsm-logisticsGRUEN-5.compressed.pdf (accessed 5 March 2020).

15. Bobylev S., Perelet R. Ekologicheskaya informatsiya i obrazovanie v oblasti ustoychivogo razvitiya [Environmental information and sustainable development education]. Ustoychivoe razvitie $v$ Rossii [Sustainable development in Russia]. Available at: https://www.austausch.org/files/DRA/Publikationen/Nachhaltige_ Entwicklung_in_Russland.pdf (accessed 5 March 2020).

16. Rail and sustainable development. International Union of Railways, 2011. Available at: https://www.vialibre-ffe.com/pdf/7180.pdf (accessed 5 March 2020).

17. McKinsey on sustainability \& resource productivity. Sustainability \& Resource Productivity, 2016 , № 4. Available at: https://www.mckinsey.com/ /media/McKinsey/Business Functions/Sustainability/Our Insights/McKinsey on Sustainability and Resource Productivity Number 4/McKinsey on Sustainability and Resource Productivity Issue 4.ashx (accessed 5 March 2020).

18. Sustainability in logistics and supply chain management. Hamburg International Conference on Logistics, 2015. Available at: https://tore.tuhh.de/bitstream/11420/1266/1/HICL 2015 - Vol 21 - Sustainability in Logistics and Supply Chain Management.pdf (accessed 5 March 2020).

19. Grabara J. Sustainable logistics management. Editura Universităţii "Lucian Blaga" din Sibiu, 2013. Available at: https://www.researchgate.net/publication/266854152_sustainable_logistics_management (accessed 5 March 2020).

20. Guilherme F. Measuring performance in rail freight transportation companies. International Business Research, 2017, vol. 10, no. 11. DOI: 10.5539/ibr.v10n11p117.

21. The Future of rail. Opportunities for energy and the environment. International energy agency, 2019. $175 \mathrm{p}$. Available at: https://www.shop-etf.com/en/the-future-of-rail (accessed 5 March 2020).

22. Sustainability strategy. SBB Swiss Federal Railways, 2020. Available at: https://company.sbb.ch/en/thecompany/responsibility-society-environment/sustainability-strategy.html (accessed 21 February 2020).

23. Eco-friendly paving stones from AB. Deutsche Bahn AG, 2020. Available at: https://gruen.deutschebahn.com/en/measures/pavingstones (accessed 21 February 2020).

24. Evans B. SA should look to China for sustainable rail solutions. EE Publishers (Pty) Ltd, 2014. Available at: https://www.ee.co.za/article/sa-look-china-sustainable-rail-solutions.html (accessed 23 February 2020). 
25. RZhD $\mathrm{v}$ tsifrakh [Russian railways in numbers]. Russian Railways OJSC. Available at: https://www.rzd.ru/static/public/ru?STRUCTURE_ID=5232 (accessed 2 March 2020).

26. Obzor otrasli gruzoperevozok $v$ Rossii, 2019 god [Overview of the freight industry in Russia, 2019]. Available at: https://www.ey.com/publication/vwluassets/ey-transportation-services-2019-rus/\$file/eytransportation-services-2019-rus.pdf (accessed 2 March 2020).

27. Otraslevye dokumenty strategicheskogo planirovaniya [Industry strategic planning documents]. Sayt Pravitelstva Rossii [Website of the Government of Russia]. Available at: http://government.ru/rugovclassifier/625/events/ (accessed 14 March 2020).

28. Provornaya E. Mitya Savelov (Change.org): «Lichnye istorii - samye glavnye dvigateli lyubykh peremen» [Mitya Savelov (Change.org): «Personal stories are the most important drivers of any change»]. GQ. Available at: https://www.gq.ru/success/mitya-savelov-changeorg (accessed 1 March 2020).

29. Bobylev S., Perelet R. Ustoychivoe razvitie i zelenaya ekonomika v Rossii: aktualnaya situatsiya, problem i perspektivy [Sustainable development and the green economy in Russia: current situation, problems and prospects]. Ustoychivoe razvitie $v$ Rossii [Sustainable development in Russia]. Available at: https://www.austausch.org/files/DRA/Publikationen/Nachhaltige_Entwicklung_in_Russland.pdf (accessed 5 March 2020).

30. Nureev R. Ekonomicheskie sanktsii protiv Rossii: ozhidaniya i realnost [Economic sanctions against Russia: expectations and reality]. Moscow, KNORUS Publ., 2017. 194 p.

31. Lukyanova O., Khusainov F. O konkurentsii zheleznodorozhnogo i avtomobilnogo transporta na rynke gruzovykh perevozok [On competition of rail and road transport in the freight market]. Vektor transporta, 2014 , no. 2, pp. 28-43.

32. Strategiya ustoychivogo razvitiya [Sustainable development strategy]. Business magazine in the field of CSR and Sustainable Development «Sustainable Business». Available at: http://csrjournal.com/strategiyaustojchivogo-razvitiya (accessed 22 February 2020).

33. Ovsyannikov I. Eurasianet (SShA): Rossiya perezhivaet novy vsplesk emigratsii [Eurasianet (USA): Russia is experiencing a new surge in emigration]. Available at: https://inosmi.ru/social/20190716/245475409.html (accessed 29 February 2020).

34. Bakatina D., Duviesar J.P., Klintsov V., Krogmann K., Remes J., Solzhenitsyn E., Shvakman I. Effektivnaya Rossiya. Proizvoditelnost kak fundament rosta [Effective Russia. Performance as a foundation for growth]. Available at: http://gtmarket.ru/files/news/1986/MGI_Effective_Russia_Productivity_Growth_as_the_ Foundation_2009.pdf (accessed 3 March 2020).

35. «VSTO-2» pereorientiruet chast nefti s zheleznoy dorogi na truboprovodny transport [ESPO-2 will reorient part of oil from the railway to pipeline transport]. Available at: http://www.gudok.ru/ freighttrans/?ID=1302708 (accessed 3 March 2020).

36. Pisareva V. Obshchie problemy ekologii Rossiyskoy Federatsii [General environmental problems of the Russian Federation]. International Institute for Humanitarian and Political Studies. Available at: http://www.igpi.ru/monitoring/1047645476/oct_93/1058173260.html (accessed 20 February 2020).

37. V $20 \%$ gorodov Rossii zagryaznenie vozdukha otsenivayetsya kak vysokoe i ochen vysokoe [In $20 \%$ of Russian cities, air pollution is rated as high and very high]. TASS News Agency. Available at: https://tass.ru/obschestvo/3913243 (accessed 20 February 2020).

38. Popravko N. Kontrol za ispolneniem prirodookhrannogo zakonodatelstva, obzor sudebnoy praktiki [Monitoring compliance with environmental legislation, review of judicial practice]. Ustoychivoe razvitie $v$ Rossii [Sustainable development in Russia]. Eds. S. Bobylev, R. Perelet. Available at: https://www. austausch.org/files/DRA/Publikationen/Nachhaltige_Entwicklung_in_Russland.pdf (accessed 5 March 2020).

39. Khmeleva E. Pravovye aspekty: sostoyanie pravovogo polya i pravovoy praktiki [Legal aspects: state of the legal field and legal practice]. Ustoychivoe razvitie $v$ Rossii [Sustainable development in Russia]. Eds. S. Bobylev, R. Perelet. Available at: https://www.austausch.org/files/DRA/Publikationen/Nachhaltige_ Entwicklung_in_Russland.pdf (accessed 5 March 2020).

Received: 15 March 2020. 